\title{
Attachment in OCD: A meta-analysis
}

W.A. van Leeuwen ${ }^{1}$, G.A. van Wingen ${ }^{1}$, P. Luyten ${ }^{2,3}$, D. Denys ${ }^{1}$, H.J.F. van Marle ${ }^{1,4,5}$

1. Amsterdam UMC, University of Amsterdam, Department of Psychiatry, Amsterdam Neuroscience, Meibergdreef 5, PO Box 22660, 1100 DD Amsterdam, The Netherlands

2. Faculty of Psychology and Educational Sciences, University of Leuven, Tiensestraat 102, PO box 3720, 3000 Leuven, Belgium

3. Research Department of Clinical, Educational and Health Psychology, University College London, 1-19 Torrington Place, London WC1E 7HB, UK

4. Amsterdam UMC, Vrije Universiteit Amsterdam, Department of Psychiatry, Amsterdam Neuroscience, De Boelelaan 1117, 1081 HV, Amsterdam, The Netherlands

5. GGZ inGeest Specialized Mental Health Care, Research and Innovation, Oldenaller 1, $1081 \mathrm{HJ}$, Amsterdam, The Netherlands.

Corresponding author: Wieke van Leeuwen, Amsterdam UMC, Location AMC, Meibergdreef 5, Room PA3-118, PO Box 22660, 1100 DD Amsterdam, The Netherlands.

Email: w.a.leeuwenvan@amsterdamumc.nl. Telephone: 0031-20-8913600 


\section{Abstract}

\section{Introduction}

It has been proposed to extend the cognitive-behavioral model of obsessive-compulsive disorder (OCD) with attachment theory to shed light on the affective and developmental factors underlying the disease. With a growing number of empirical studies on the subject, this meta-analysis aims to quantify a possible relationship between attachment insecurity and OCD.

\section{Methods}

A systematic search was conducted for studies in adult populations of patients with OCD as well as general populations displaying symptoms of OCD. Effect sizes of attachment anxiety and attachment avoidance were calculated separately. Covariates of demographic variables were used in meta-regressions.

Results

Sixteen studies were included. Meta-analyses showed an association of medium to large effect size (Hedges' $g=0.69 ; 95 \%$ CI $0.58-0.80 ; p<0.001$ ) between OCD and attachment anxiety, and an association of medium effect size (Hedges' $g=0.47$; 95\% CI $0.39-0.54 ; \mathrm{p}<$ 0.001 ) between OCD and attachment avoidance. Effect sizes in OCD population and general population studies did not differ significantly.

\section{Discussion}

Robust effect sizes of both attachment anxiety and avoidance in relation to OCD symptomatology corroborate an attachment-centred view of OCD. These findings furthermore suggest that integrating cognitive and attachment-based therapeutic approaches to OCD may benefit patients in which developmental or emotional factors hinder successful treatment.

\section{Highlights:}

- Both attachment anxiety and attachment avoidance are associated with OCD (symptoms)

- No differences were found between clinical and non-clinical populations

- These findings support attachment approaches to OCD

- Combining cognitive and attachment-based strategies may improve OCD treatment

\section{Keywords: obsessive compulsive disorder; attachment; psychodynamic; systematic review; meta-analysis}




\section{Introduction}

Patients with obsessive-compulsive disorder (OCD) suffer from obsessions and/or compulsions. Obsessions are unwanted, recurrent and persistent thoughts, images or impulses that evoke anxiety or extreme distress. In order to relieve these negative emotions, patients feel forced to execute repetitive behavioural or mental acts, known as compulsions. Despite awareness of the unreasonable nature of symptoms, patients are caught in this timeconsuming repertoire (American Psychiatric Association, 2013).

The psychological perspective on OCD has been dominated for the past four decades by the cognitive-behavioural model (e.g. Rachman 1997, 1998; Salkovskis, 1985) after the psychodynamic perspective lost its influence in the field of OCD (Esman, 2001). The cognitive-behavioural model states that OCD patients develop symptoms because they draw catastrophic inferences from intrusive thoughts. These cognitive biases are thought to emerge from dysfunctional beliefs, such as perfectionism and overestimation of threat (Obsessive Compulsive Cognitions Working Group, 1997). Risk-avoidant compulsive behaviour leaves these misinterpretations unchallenged, further enhancing the obsessive-compulsive cycle.

Critique on this model is that the affective traits and developmental determinants underlying these cognitive coping mechanisms are given little attention (Doron \& Kyrios, 2005). Currently, psychodynamic psychotherapy by itself is not considered an effective treatment for OCD (Gabbard, 2005; National Institute for Health and Clinical Excellence, 2005). More recently, however, it has been suggested to extend the cognitive-behavioural framework with a psychodynamic view on OCD (symptoms) centring on attachment functioning (Doron \& Kyrios, 2005; Doron \& Moulding, 2009; Kempke \& Luyten, 2007; Sookman \& Pinard, 1999). This has the ultimate goal of integrating cognitive and attachment-based therapeutic approaches to OCD and thereby increasing therapeutic effectiveness.

According to attachment theory (Bowlby 1969/1982, 1973, 1980) people have a basic need to receive comfort and support from close others in times of stress or hurt. During early childhood, interactions with primary caregivers, and the degree to which parental responses are consistent and congruent to the emotional needs of the child, are internalized as mental schemas of self and others. These schema's subsequently have an impact on relationships, self-esteem, emotion regulation and mental health throughout life (Mikulincer \& Shaver, 2007). The quality of these internalized interactions determines the adult attachment style, which can be measured along two orthogonal dimensions, attachment-related anxiety and attachment-related avoidance (Bartholomew, 1997; Bartholomew \& Horowitz, 1991; 
Brennan et al., 1998). High scores on anxious or avoidant attachment (or both) are equivalent to an insecure attachment style. Attachment anxiety is characterized by chronic worry about the unavailability of important others and a strong fear of abandonment (Bartholomew, 1997; Bartholomew \& Horowitz, 1991; Brennan et al., 1998). Stressful situations induce a hyperactivation of the attachment system, resulting in increased vigilance for threats and excessive reassurance seeking (Mikulincer et al., 2003). Attachment avoidance, on the other hand, is characterized by a dominant fear of closeness, and not tolerating intimacy with others out of a desire for control and autonomy. Here, stressful situations induce deactivation of the attachment system, resulting in over-regulation (suppression) of negative emotions and social withdrawal (Fraley \& Shaver, 1997; Mikulincer et al., 2003). Fearful avoidance, with high anxious and avoidant characteristics, is thought to evolve out of traumatic attachment experiences such as loss or abuse (Hesse \& Main, 2000). Individuals with low scores on both attachment dimensions are considered to be securely attached, and are able to rely on others in an autonomous fashion and adequately regulate their emotions.

Attachment insecurity is seen as a vulnerability factor for developing psychopathology in general (Bakermans-Kranenburg \& van IJzendoorn, 2009; Mikulincer \& Shaver, 2007). With respect to OCD, attachment insecurity (both anxiety and avoidance) has been directly associated with symptoms by predicting dysfunctional OCD-related beliefs (Doron et al, 2009). It is thus suggested that an insecure attachment style increases vulnerability to OCD. These data are supported by the work of several authors concluding that both attachment anxiety and avoidance are associated with the same dysfunctional cognitive processes that make up current cognitive models of OCD (Obsessive Compulsive Cognitions Working Group, 1997). For instance, attachment anxiety is associated with exaggerated threat appraisals (Mikulincer \& Florian, 1998), maladaptive perfectionism (e.g. Wei et al., 2004) and difficulties in suppressing unwanted thoughts (Fraley \& Shaver, 1997). Attachment avoidance is associated with setting high, unrealistic and rigid personal standards of excellence (Rice et al., 2005). On a theoretical level, it is associated with a tendency to base one's world perspective on rational thought (Blatt \& Shichman, 1983), corresponding to the belief domains of the over-importance of one's thoughts and the need to control them (Kempke \& Luyten, 2007). Furthermore, parallels have been drawn between dysfunctional OCD-related beliefs, like inflated responsibility, and psychodynamic defense mechanisms (Kempke \& Luyten, 2007; Moritz et al., 2010). Finally, it is assumed that emotion-regulating strategies in insecurely attached individuals fail to down regulate catastrophic interpretations of intrusive thoughts (Doron \& Kyrios, 2005; Doron \& Moulding, 2009; Doron et al., 2015; 
Ein-Dor et al., 2016). All these factors increase vulnerability to develop obsessional preoccupations and disabling compulsive behaviours. In addition, inadequate social support seeking, related to attachment insecurity, could manifest itself in the persistence of compulsive self-soothing behaviour, characteristic of OCD (Carpenter \& Chung, 2011).

Following up on this new attachment-centred conceptualisation of OCD, we aimed to quantify a possible relationship between OCD and attachment functioning by performing a meta-analytic review on all empirical studies published so far on this subject. A growing number of studies have investigated the relationship between OCD and attachment, but results are mixed and difficult to compare. Besides determining an estimate of the effect size, we aimed to synthesize the existing literature and examine the role of potential moderators of the proposed relationship. In addition, we aimed to identify which insecure attachment type (i.e., anxious or avoidant) is specifically associated with OCD, as individual studies are inconsistent on this topic. We included both clinical studies (in patients diagnosed with OCD) and non-clinical studies (in healthy populations displaying symptoms of OCD), since OCD symptoms are believed to follow a dimensional rather than a categorical distribution (Olatunji et al., 2008).

\section{Methods}

\subsection{Database searches}

We conducted the meta-analysis in accordance with the PRISMA guidelines (Moher et al., 2009). To quantify a possible relationship between attachment insecurity and OCD (symptoms), we searched the databases PsycINFO, PubMed and Embase for papers published until May 2019 with the terms attachment AND (obsessive compulsive disorder OR obsessive compulsive symptoms OR obsessive OR obsessions OR compulsive OR compulsions) in the title or abstract. No restrictions were made for study design. Reference lists of studies considered for inclusion and relevant review papers were scanned for empirical papers missed by the database search.

\subsection{Study selection}

All titles and abstracts were screened by WvL Studies that potentially matched the inclusion criteria were examined in full-text. In case of inconclusiveness, studies were included on the basis of agreement between WvL and HvM. The selection of studies for inclusion in the meta-analysis was made using the following inclusion and exclusion criteria, which were formulated in advance: (a) Papers had to be written in English or Dutch. (b) The populations 
investigated in the studies had to be adult. (c) Papers had to report primary data. (d) Assessments of attachment style had to be reported. To avoid ambiguity of the construct, only measurements based on definitions of Ainsworth et al. (1978) were included (for an overview, see Mikulincer \& Shaver, 2007; Crowell et al., 1999). Constructs could assess attachment either on a dimensional or categorical scale. (e) Diagnostic assessments of OCD had to be reported, including clinical diagnosis according to DSM or ICD criteria or questionnaires measuring OCD symptoms. Questionnaires measuring OCD symptoms were suitable if they were developed to identify OCD symptom presence or severity (for an overview see Storch et al., 2011; Rapp et al., 2016). Studies that reported only results of questionnaires that measure ancillary features or sub-dimensions of OCD, such as the Obsessive Beliefs Questionnaire (Obsessive Compulsive Cognitions Working Group, 2003) or the Relationship Obsessive-Compulsive Inventory (Doron et al., 2012a) were excluded. Studies that covered primarily hoarding symptoms were excluded. Although hoarding can be a symptom of OCD, it does not necessarily indicate OCD (Tolin et al., 2011), and in DSM-5 hoarding disorder is categorized separately from OCD (American Psychiatric Association, 2013). (f) Studies were excluded if the minimum required statistical information for calculating an effect size was lacking. For studies that compared an OCD sample with a control group, reports on mean and group number in combination with standard deviation or $p$-value on $t$-test outcome were needed. For studies that reported proportions of attachment categories within an OCD sample, numbers from a comparison group were needed to calculate an odds ratio. For studies that investigated OCD symptoms and attachment style within an OCD or general population sample, a correlation coefficient or the possibility to extract such a correlation coefficient from the reported outcome was needed.

\subsection{Data extraction}

For the studies judged eligible for inclusion in the meta-analysis, the following data, if present, were extracted: Study characteristics (year of publication, country, study design, use of clinical population, instrument of OCD assessment, instrument of attachment assessment) and subject characteristics (number, mean age, gender, relationship status, education level, OCD severity, OCD symptom subtype, attachment style, additional assessments on depression, anxiety and personality dimensions or disorders).

With regard to attachment assessment, the group of selected studies used several different scales. A widely used construct in empirical studies is the Experiences in Close Relationships scale (ECR; Brennan et al., 1998), which measures attachment anxiety and 
attachment avoidance separately. This scale resulted from factor analysis of items from all preceding self-report attachment scales that were in use at the time of development. In studies in which a scale other than the ECR was used, the attachment score was extracted as follows. The Revised Adult Attachment Scale (Collins \& Read, 1990) consists of three subscales. One, named "anxious concern about being abandoned or unloved", corresponds to the attachment anxiety dimension of the ECR, and the other two, named "discomfort with closeness" and "discomfort with depending on others", both correspond to the attachment avoidance dimension of the ECR (Brennan et al., 1998). In one of the included studies (Asad $\&$ Dawood, 2015), both of these subscales were combined in one effect size of attachment avoidance, which we included in the meta-analysis. Another study (Koohsar \& Bona, 2011) reported on the two avoidant subscales separately. In this case, we selected the "discomfort with closeness" subscale for inclusion in the attachment avoidance meta-analysis, because of the highest correlation with attachment avoidance (0.86; Brennan et al., 1998). The Reciprocal Attachment Questionnaire (West \& Sheldon-Keller, 1992) consists of four subscales that measure scores on attachment insecurity. We selected the subscale "feared loss" (covering items that show anxiety about abandonment), which shows a correlation of 0.64 with the anxiety dimension of the ECR (Mikulincer \& Shaver, 2007), to include in the attachment anxiety meta-analysis, and the subscale "secure base" (covering items that show the respondent's reliance on the attachment figure), which shows a correlation of 0.79 with the avoidance dimension of the ECR (Mikulincer \& Shaver, 2007), to include in the attachment avoidance meta-analysis. The Relationship Questionnaire (Bartholomew \& Horowitz, 1991) categorizes respondents in four prototypic attachment patterns: secure, preoccupied, dismissing and fearful, of which preoccupied corresponds to attachment anxiety and dismissing to attachment avoidance.

In one study (Asad \& Dawood, 2015), more than one outcome of the correlation between attachment and OCD was reported (for distinct OCD symptom categories separately). In this case we chose to extract results of the overall obsession scale.

In all eligible studies, statistical data on the relation between OCD and attachment style were extracted for calculation of effect size. In studies that reported multiple effect sizes, we chose the following hierarchical order: differences in means (between attachment style in OCD group versus control group) over correlation (between attachment style and OCD severity) over odds ratio (when cut-off scores were used to transform dimensional attachment scores into categorical attachment scores). In one study (Gülüm \& Dağ, 2014), outcome data of the correlation between attachment styles and OCD symptoms were reported 
for men and women separately. For this reason, two effect sizes from this study were included in the meta-analysis. Tibi and colleagues (Tibi et al., 2017) provided us with the necessary effect sizes that were not available in their published study.

\subsection{Meta-analysis}

Meta-analytic computations were conducted using Comprehensive Meta-Analysis software version 3.0 (Biostat, Englewood, NJ, USA). A random effects model was used, as betweenstudy variability in effect sizes could be assumed based on differences in subject features and data collection (Borenstein et al., 2009). Studies were labelled as OCD population when an OCD group was included and as general population when assessments were done in ample form a healthy population. Effect sizes for attachment anxiety and attachment avoidance were calculated separately. Effect sizes expressed in differences in means and correlation coefficients were converted to individual Hedges' $g$ effect sizes according to Borenstein et al. (2009), to allow pooling of the effect sizes. Pooled effect sizes were estimated for $O C D$ population and general population studies separately and for both categories combined.

The amount of heterogeneity was estimated by calculating $I^{2}$. Values around $25 \%$ could be considered as low heterogeneity (Higgins et al., 2003). Publication bias was assessed by examining funnel plots supplemented with Duval and Tweedie's trim and fill method (Duval \& Tweedie, 2000).

\subsection{Covariates}

Additional analyses of covariates were performed with separate meta-regressions for mean age, gender, relationship status, and years since publication. Because of the limited number of studies, it was not valid to run them together, so we applied the meta-regressions sequentially. Countries in which the studies were conducted were grouped by continent and a subgroup analysis was run to study possible topographic effects on variance in effect size. Data on comorbidity of depression, anxiety, and personality dimensions or disorders, OCD severity, OCD symptom subtype and education level were insufficient to administer in a meta-regression.

\subsection{Additional measurements}

In order to interpret the clinical significance of differences in attachment anxiety and avoidance scores between OCD and healthy control groups in the case-control studies, we compared the mean attachment scores of both populations with norm scores (Conradi et al., 
2018). As only norm scores of the ECR were available, we applied this comparison to the case-control studies that made use of this instrument.

\section{Results}

\subsection{Included studies}

\subsubsection{Study selection}

The study selection procedure is depicted in Figure 1. The search resulted in 381 hits, of which 72 articles potentially matched our inclusion criteria based on screening of the title and abstract. These articles were assessed in full-text for eligibility, and 16 studies were included in the meta-analysis. The main reason for exclusion was the absence of a (valid) measure for attachment style or OCD (symptoms) that fulfilled our inclusion criteria. Furthermore, a substantial number of studies were written in a language other than English or Dutch, or reported statistics in a way that did not fulfil our inclusion criteria. Of the 16 included studies, eight were performed in a sample of OCD patients and eight were performed in a sample of healthy control subjects (i.e., general population sample). We classified one study that made use of an OCD-analogue group as an OCD population study. From all the studies except two (Myhr et al., 2004; Seah et al., 2018), it was possible to extract effect sizes for attachment anxiety as well as attachment avoidance. In the studies of Myhr and colleagues and Seah and colleagues we could extract an effect size only for attachment anxiety.

\subsubsection{Number of patients and controls}

With respect to the case-control studies, attachment insecurity levels were analysed in a total sample of 212 patients with OCD and 307 healthy controls. Concerning the correlational studies, attachment insecurity levels in relation to obsessive-compulsive symptoms were analysed in a total group of 468 OCD patients and 3402 individuals from the general population.

\subsubsection{Study characteristics}

Data extracted and a summary of the main results of each included study is provided in Table 1. All studies were performed cross-sectionally with either a case-control or a correlational design. Five out of eight OCD population studies included a healthy control group.

As shown in Table 1, all studies used self-report questionnaires to measure adult attachment style, which have shown adequate reliability and validity (reviewed by Mikulincer \& Shaver, 2007). In eight studies the attachment questionnaires were formulated 
with regard to romantic partners; the remaining eight studies asked participants to think of close relationships in general (e.g. romantic partners, close friends or family members) while answering the questions. In eleven studies the ECR or an adapted version was used.

As further summarized in Table 1, in five of the OCD population studies OCD diagnosis was confirmed by clinical interview using DSM-IV criteria. In three studies selfreport assessments of OCD were used. In six OCD population studies, additional OCD severity scores were reported; however, correlation with attachment outcome was calculated in only three studies. The general population studies used diverse symptom severity questionnaires.

\subsection{Meta-analysis}

\subsubsection{Attachment anxiety}

As shown in Figure 2, the meta-analysis showed an association of medium to large effect size (Cohen, 1987) between OCD and attachment anxiety (Hedges' $g=0.69 ; 95 \%$ CI $0.58-0.80$; $p<0.001)$ when the OCD and general population studies were pooled. When comparing populations, the effect size in the OCD population studies (Hedges' $g=0.63 ; 95 \%$ CI $0.28-$ $0.98 ; p<0.001$ ) was slightly lower than in the general population studies (Hedges' $g=0.69$; $95 \%$ CI $0.58-0.81 ; p<0.001)$, although this difference was not significant $\left(Q_{b e t}=0.12, d f=\right.$ $1, p=0.73)$.

Moderate heterogeneity was found across general population studies $\left(I^{2}=61.6 \%\right)$. High heterogeneity was found across OCD population studies $\left(I^{2}=82.5 \%\right)$ and across all studies $\left(I^{2}=78.7 \%\right)$ (Higgins et al., 2003). To search for a possible explanation of the variability of effect sizes, we applied consecutive meta-regressions on effect size of the moderators years after publication, age, gender, and relationship status. None of these metaregressions showed a significant effect. Furthermore, comparison of effect sizes between the different continents where the studies were performed did not show a significant difference.

To estimate publication bias, we inspected the funnel plot in combination with Duval and Tweedie's trim and fill algorithm. This showed four small studies missing on the left side of the effect size. To account for the possible publication bias, we calculated the adjusted effect size. This was Hedges' $g=0.61$, which was not much different from the original effect size. 


\subsubsection{Attachment avoidance}

As shown in Figure 3, the meta-analysis showed an association of medium effect size between OCD and attachment avoidance (Hedges' $g=0.47$; 95\% CI $0.39-0.54 ; p<0.001$ ) when the OCD and general population studies were pooled. When comparing populations, the effect size in the OCD population studies (Hedges' $g=0.45 ; 95 \% \mathrm{CI} 0.15-0.74 ; p=$ 0.003 ) was slightly lower than in general population studies (Hedges' $g=0.47$; CI 0.39 $0.55 ; p<0.001)$, although this difference was not significant $\left(Q_{b e t}=0.02, d f=1, p=0.88\right)$.

Very low heterogeneity was found across the general population studies $\left(I^{2}=4.6 \%\right)$. High heterogeneity was found across OCD population studies $\left(I^{2}=74.7 \%\right)$. Heterogeneity across all studies was moderate $\left(I^{2}=59.9 \%\right)$ (Higgins et al., 2003). To search for a possible explanation of the variability of effect sizes, we applied consecutive meta-regressions on effect size of the moderators years after publication, age, gender, and relationship status. None of these meta-regressions showed a significant effect. Furthermore, comparison of effect sizes between the different continents where the studies were performed did not show a significant difference.

To estimate publication bias, we inspected the funnel plot in combination with Duval and Tweedie's trim and fill algorithm. This showed four studies missing on the left side of the effect size. To account for the possible publication bias, we calculated the adjusted effect size. This was Hedges' $g=0.41$, which was not much different from the original effect size.

\subsection{Clinical interpretation of attachment scores}

For the four case-control studies that made use of the ECR, we compared mean attachment scores with population-based norm scores provided by Conradi et al. (2018). Three out of the four studies (Carpenter \& Chung, 2011; Doron et al., 2012b; Marazziti et al., 2015) showed anxiety scores of the OCD group that fell in the two highest stanines, which reflect problems related to attachment anxiety (Conradi et al., 2018). The mean attachment anxiety score of the OCD group in the fourth study (Alcee, 2006) fell in the 6th to 7th stanine, reflecting suspected problems related to attachment anxiety. In comparison, the mean attachment anxiety scores of the healthy control group in two studies (Carpenter \& Chung, 2011; Doron et al., 2012b) were suspect for problems related to attachment anxiety, while scores in the other two studies (Alcee, 2006, Marazziti et al., 2015) indicated the absence of problems related to attachment anxiety. Furthermore, all four studies showed mean attachment avoidance scores of the OCD group that fell into the category of suspected problems related 
to attachment avoidance. In comparison, mean attachment avoidance scores of the healthy control group in these studies did not indicate problems related to attachment avoidance.

\section{Discussion}

\subsection{Main results}

In this meta-analysis we set out to assess the association between OCD symptomatology and attachment insecurity. Pooling data from eight OCD population studies and eight general population studies, we found an association between attachment anxiety and OCD symptomatology, with a medium to large effect size. No significant difference in effect size was observed between the OCD and general population studies. The same analysis for attachment avoidance (with the omission of one OCD population study and one general population study from the dataset) resulted in an association of medium effect size. Again, no significant difference in effect size was found between the OCD and general population studies. Age, gender, relationship status, years after publication and topographical region did not affect the associations found.

To increase power and reduce publication bias, this meta-analysis was not limited to clinical studies in OCD patients, but as well included studies reporting on OCD symptomatology in a general (healthy) population sample. This approach is justified when the variables tested are assumed to be dimensional and not restricted to a certain range in the populations under study (Abramowitz et al., 2014). Both obsessive-compulsive symptoms (Olatunji et al., 2008; Abramowitz et al., 2014) and attachment insecurity (e.g. Brennan et al., 1998) meet this criterion. The fact that we did not find a significant difference in the association strength between attachment insecurity and OCD symptomatology between the OCD population studies and general population studies implies that the association is not affected by whether the person has a diagnosis of OCD or not. This is notwithstanding the fact that both attachment anxiety and avoidance scores were significantly higher in the OCD samples tested than in the healthy control groups. So, even though the association between attachment insecurity and OCD symptomatology reflects a more pathological state among patients, the association seems to exist also in a subclinical population. Furthermore, with respect to population-based norm scores on attachment (Conradi et al., 2018), the mean reported attachment anxiety and avoidance scores in the clinical studies (i.e. four casecontrol studies that used the ECR) implicate (suspected) problems related to attachment insecurity, indicating the clinical relevance of the results. 


\subsection{An attachment perspective on $O C D$}

This meta-analysis corroborates the attachment-centred view on OCD, as propagated by a small but growing conceptual literature (e.g. Doron \& Kyrios, 2005; Kempke \& Luyten, 2007). Central in these theories is that attachment insecurity is seen as an underlying vulnerability factor for developing dysfunctional cognitive beliefs that are central to OCD (i.e., exaggerated threat appraisal for anxiously attached OCD patients, and over-importance of thoughts for avoidantly attached patients). Furthermore, inadequate affect regulation in response to alarming or threatening thoughts renders each intrusion a possible obsession (Doron \& Kyrios, 2005; Doron \& Moulding, 2009; Doron et al., 2015; Ein-Dor et al., 2016). Attachment anxiety and attachment avoidance are thereby respectively related to hyperactivation and deactivation of the attachment system, resulting in hypervigilance towards, or distancing oneself from, potential threatening and attachment-related cues.

By showing a medium to strong association between attachment insecurity and OCD symptomatology, our meta-analysis provides empirical support for an attachment perspective on OCD. As discussed above, we found both attachment anxiety and attachment avoidance to be related to OCD symptoms. Given the fact that OCD is a heterogeneous disorder, attachment anxiety could be related to OCD symptom dimensions different from those related to attachment avoidance. The only two studies that reported on separate correlations between insecure attachment style and OCD symptom dimensions did not find such a distinction, although these studies were performed in general (healthy) population samples (Doron et al., 2009; Boysan \& Çam, 2018). Future clinical studies could assess whether distinct OCD subtypes are related to a specific insecure (or secure) attachment style.

These data seem to highlight the importance of developmental factors underlying OCD. Although the genetic contribution to OCD is estimated at around 40\% (Brander et al., 2016), little is known about environmental risk factors that interact with this genetic risk. A recent review suggests that perinatal complications, reproductive cycle events, and stressful or traumatic life events could play an aetiological role in OCD (Brander et al., 2016). As traumatic life events can additionally affect attachment style (Waters et al. 2000), both OCD and attachment insecurity could be parallel effects of the same precursor. Alternatively, maladaptive attachment could mediate the development of OCD after a traumatic event. Although our meta-analysis does not allow us to study a possible moderating effect of traumatic life events, our data do corroborate the notion that developmental factors play a role in OCD. 
Importantly, insecure attachment does not seem to be specific for OCD (BakermansKranenburg \& van IJzendoorn, 2009). Depressive and anxiety disorders have also been shown to be associated with both attachment anxiety and attachment avoidance (Mikulincer \& Shaver, 2007), whereas posttraumatic stress disorder is specifically linked to attachment anxiety (Woodhouse et al., 2015). This meta-analysis does not allow a direct comparison of attachment functioning to be made across these different disorders, but the conceptual models linking (maladaptive) attachment to specific symptoms do differ (Ein-Dor et al., 2016). In the case of OCD, we could argue that both an anxious and an avoidant attachment style, possibly in interaction with other developmental factors such as traumatic life events, form a vulnerability factor for the development of OCD.

\subsection{Clinical implications}

Our findings indicate that attachment theory could be used to extend the current cognitivebehavioural model of OCD by emphasizing developmental and emotional factors that underlie dysfunctional beliefs and fuel the obsessive-compulsive cycle. Cognitivebehavioural therapy (CBT) is based on techniques of exposure and response prevention and cognitive challenging of dysfunctional appraisals. Although CBT has been extensively shown to be effective in treating OCD, approximately half of OCD patients prematurely drop out of treatment or do not respond sufficiently, and only $25 \%$ achieve complete recovery (Abramowitz, 2006; Eddy et al., 2004). An essential ingredient of CBT is for the patient to behaviourally break through the habitual nature of the symptoms. Therapy resistance often results from patients not daring to fully participate in exposure practices that form a part of CBT. A schema-based extended CBT (Sookman \& Pinard, 1999) can be used to explore this resistance, by analyzing early attachment experiences and self-perception and their effect on explicit as well as tacit emotional, cognitive, and behavioral reactions to internal and external stressors. This could clarify motivational processes in maintaining symptoms and, with this insight, remove boundaries to participating in therapy, as well as prevent relapse. Currently, only few studies in regular CBT-resistant OCD patients have tested this type of attachmentbased augmented CBT (Sookman \& Pinard, 1999; Thiel et al., 2016). There is also an urgent need for studies on the efficacy of other types of psychotherapy that are explicitly rooted in attachment views, such as contemporary psychodynamic treatment for OCD (Leichsenring \& Steinert, 2017).

Alternatively, information on attachment style could inform on therapeutic progress, or lack thereof. Independent of OCD, attachment anxiety (but not attachment avoidance) has 
recently been shown to predict poorer outcomes of CBT in a group of patients with anxiety disorder (Nielsen et al., 2018). This observation could be related to these patients' inability to tolerate emotionally arousing states, preventing their full participation in exposure practices (Nielsen et al., 2018). A similar mechanism could apply to OCD. Finally, attachment insecurity could play a role in therapy resistance by disturbing the working alliance with the therapist (Bernecker et al., 2014).

\subsection{Limitations}

Although the effect sizes in our meta-analysis show robust associations between attachment insecurity and OCD symptomatology, the limitations of this study must be considered. First, as we could include only correlational and cross-sectional studies, we cannot make inferences on the (temporal) causality of the observed associations. On the one hand, OCD impacts highly on social functioning. Not only do symptoms reduce patients' mental capacity to invest in interpersonal activities, in many cases patients also force their partners or family members to accommodate them in their symptom repertoire (Rosa et al., 2012). This could negatively affect both the relationships themselves as well as patients' attitudes towards the people around them. Alternatively, core characteristics of a person's relatedness to others, as expressed by attachment style, could form a vulnerability factor in the development of OCD. By showing that mere OCD tendencies or subthreshold symptoms (and not full diagnosis) are associated with anxious and avoidant attachment, our data may indicate that attachment insecurity precedes the manifestation of OCD and is itself not necessarily a result of the impairment associated with such a mental disorder. Earlier research showing a longitudinal effect of attachment insecurity on the development of either an anxiety disorder (Warren et al., 1997) or a major depressive disorder (Bifulco et al., 2002) supports this reasoning. A similar longitudinal design assessing attachment (in)security and (the development of) OCD symptomatology is needed to draw any definite conclusions about causality. However, this will be experimentally challenging owing to the large number of subjects needed. This problem could be partly overcome by studying at-risk populations, such as children of patients diagnosed with OCD (Wilcox et al., 2008).

Second, the number of studies included in the meta-analysis is small, and their overall quality was low. In the OCD population studies, low study quality was predominantly attributable to poor matching of control groups and the fact that no data were reported on comorbid depressive, anxiety or personality disorders, making it impossible to analyze these potentially important moderators. However, in the four studies that did control for comorbid 
depression (in one way or another), the association between attachment insecurity and OCD symptoms remained. Interestingly, in a longitudinal study of OCD patients, having a secure attachment style protected against the development of comorbid depression (Tibi et al., 2017). Heterogeneity was high across the OCD population studies for both the anxiety and avoidance meta-analyses. This indicates that characteristics of the study populations or assessment methods are probably quite different. It has to be noted that the dispersion of effect sizes in the OCD population studies resulted in broad confidence intervals of the combined effect sizes. Meta-regressions did not identify any moderators of the heterogeneity. Several potentially important moderators (such as comorbidity, OCD severity, OCD subtype and education level) could not be included in a meta-regression due to insufficient data, and so we cannot draw conclusions about their potential influence on the effect sizes. A possible explanation of high heterogeneity across OCD-population studies could be the difference in original type of effect size (correlational vs difference in means), as the three correlational studies are located on both ends of the forest-plots. Furthermore, a relatively large study (Tibi et al, 2017) did not find a relation between attachment insecurity and OCD severity, increasing heterogeneity. This could be due to the rather limited assessment of attachment style using the RQ, which categorizes participants based on the response to a single question, as opposed to the multi-item ECR.

In the general population studies, low quality was attributable to poor representativeness of the selected samples. Six of the eight studies included (predominantly) a student sample, of which one included students with elevated separation anxiety. Furthermore, all the studies made use of self-report measurements of attachment style and not the gold standard Adult Attachment Interview (George, Kaplan \& Main, 1984, 1985, 1996). However, the included studies used the ECR (or a comparable dimensional scale), which is a widely used and well-validated instrument (Brennan et al., 1998) that, rather than categorizing individuals into distinct attachment styles, assesses their level of attachment anxiety and avoidance. This enabled us to study the quantitative association of attachment anxiety or avoidance with OCD severity or symptom level.

Third, there was evidence of small publication bias. The adjusted effect sizes were slightly lower but not qualitatively different. The omission of a few studies based on exclusion criteria could explain the publication bias.

Fourth, as all except two studies (Boysan \& Çam, 2018; Tibi et al., 2017) reported results only for attachment anxiety and avoidance separately, almost no data were available on the association between OCD symptomatology and fearful attachment (the combination of 
high anxious and avoidant attachment) or even secure attachment. Boysan and Çam reported that participants who were classified as fearful had the highest scores on OCD symptomatology, followed by anxiously attached participants. Participants classified as avoidantly and securely attached did not differ from each other. On the contrary, Tibi and colleagues reported no significant relationships between either of the four attachment categories and OCD severity. So, even though the mean reported anxiety and avoidance attachment scores in at least the clinical studies implicate true attachment insecurity (in relation to population-based norm scores; Conradi et al., 2018), it is difficult to interpret the association found in relation to the full range of attachment (mal)functioning, varying from secure to fearful attachment organization.

\section{Conclusions}

In this meta-analysis we found a medium to large association between insecure attachment (both attachment anxiety and attachment avoidance) and OCD symptomatology (in both patients with OCD and healthy subjects with OCD symptoms). Although longitudinal designs are needed to make inferences about causality, these findings support emerging models of OCD centring on attachment malfunctioning. Furthermore, they open up the possibility of combining attachment-based therapeutic strategies, such as schema-based extended CBT, with CBT strategies in an attempt to increase therapeutic effectiveness (Doron \& Moulding, 2009; Sookman \& Pinard, 1999). Alternatively, future studies could investigate the efficacy of contemporary psychodynamic treatments for OCD. This seems particularly important in therapy-resistant cases, in which underlying developmental or emotional factors may hamper successful treatment. 


\section{Acknowledgements}

This work is supported by ZonMw grant no. 165.610.002.

Clare Farrar, Editor related to the Faculty of Psychology and Educational Sciences, University of Leuven, Belgium: provided language help.

L. Tibi, Department of Psychology, Ben-Gurion University of the Negev, Beer-Sheva, Israel: provided us with the necessary effect sizes that were not available in their published study (Tibi et al., 2017).

\section{References}

Abramowitz, J.S. (2006). The psychological treatment of obsessive-compulsive disorder. Canadian Journal of Psychiatry, 51(7), 407-16.

Abramowitz, J.S., Deacon, B.J., Olatunji, B.O., Wheaton, M.G., Berman, N.C., Losardo, D., Timpano, K.R., McGrath, P.B., Riemann, B.C., Adams, T., Björgvinsson, T., Storch, E.A., \& Hale, L.R. (2010). Assessment of obsessive-compulsive symptom dimensions: development and evaluation of the Dimensional Obsessive-Compulsive Scale. Psychological Assessment, 22, 180-198.

Abramowitz, J.S., Fabricant, L.E., Taylor, S., Deacon, B.J., McKay, D., \& Storch, E.A. (2014). The relevance of analogue studies for understanding obsessions and compulsions. Clinical Psychology Review, 34, 206-217.

Ainsworth, M.D.S., Blehar, M.C., Waters, E., \& Wall, S. (1978). Patterns of attachment: A psychological study of the strange situation. Hillsdale, NJ: Erlbaum.

Alcee, M.D. (2006). Revitalizing a relational view of obsessive-compulsive disorder: explicit and implicit measurement of the internal working models of OCD subjects. Dissertation. Ann Arbor, MI: ProQuest Information and Learning Company.

American Psychiatric Association. (2013). Diagnostic and statistical manual of mental disorders (5th ed.). Arlington, VA: American Psychiatric Association Publishing.

Asad, S., \& Dawood, S. (2015). Attachment orientation, obsessive beliefs, and symptom severity in patients with obsessive compulsive disorder, Pakistan Journal of Psychological Research, 30(2), 207-223.

Bakermans-Kranenburg, M., \& van IJzendoorn, M.H. (2009). The first 10,000 Adult Attachment Interviews: Distributions of adult attachment representations in clinical and non-clinical groups. Attachment and Human Development, 11(3), 223-263.

Bartholomew, K. (1997). Adult attachment processes: Individual and couple perspectives. British Journal of Medical Psychology, 70(3), 249-263. 
Bartholomew, K., \& Horowitz, L.M. (1991). Attachment styles among young adults: A test of a four-category model. Journal of Personality and Social Psychology, 61(2), 226244.

Bernecker, S.L., Levy, K.N., \& Ellison, W.D. (2014). A meta-analysis of the relation between patient adult attachment style and the working alliance. Psychotherapy Research, 24(1), 12-24.

Bifulco, A., Moran, P.M., Ball, C., \& Bernazzani, O. (2002). Adult Attachment style: Its relationship to clinical depression. Social Psychiatry and Psychiatric Epidemiology, $37,60-67$.

Blatt, S.J., \& Shichman, S. (1983). Two primary configurations of psychopathology. Psychoanalysis and Contemporary Thought, 6, 187-254.

Boelen, P.A., Reijntjes, A., \& Carleton, R.N. (2014). Intolerance of uncertainty and adult separation anxiety. Cognitive Behaviour Therapy, 43(2): 133-144.

Borenstein, M., Hedges, L.V., Higgins, J.P.T., \& Rothstein, H.R. (2009). Introduction to meta-analysis. Chichester, UK: John Wiley \& Sons, Ltd.

Bowlby, J. (1982/1969). Attachment and loss: Vol. 1. Attachment (2nd ed.). New York, NY: Basic Books.

Bowlby, J. (1973). Attachment and loss: Vol. 2. Separation: Anxiety and anger. New York, NY: Basic Books.

Bowlby, J. (1980). Attachment and loss: Vol. 3. Sadness and depression. New York, NY: Basic Books.

Boysan, M., \& Çam, Z. (2018). An investigation into the role of attachment insecurities in obsessive-compulsive symptoms. British Journal of Guidance \& Counselling, 46(5): 566-581.

Brander, G., Pérez-Vigil, A., Larsson, H., \& Mataix-Cols, D. (2016). Systematic review of environmental risk factors for Obsessive-Compulsive Disorder: A proposed roadmap from association to causation. Neuroscience and Biobehavioral Reviews, 65, 36-62.

Brennan, K.A., Clark, C.L., \& Shaver, P.R. (1998). Self-report measurement of adult attachment: An integrative overview. In J.A. Simpson \& W.S. Rholes (Eds.), Attachment theory and close relationships (pp. 46-76). New York, NY: Guilford Press.

Burns, G.L., Keortge, S.G., Formea, G.M. \& Sternberger, L.G. (1996). Revision of the Padua Inventory of obsessive compulsive disorder symptoms: distinctions between worry, obsessions, and compulsions. Behaviour Research and Therapy, 34(2), 163-173. 
Carpenter, L., \& Chung, M.C. (2011). Childhood trauma in obsessive compulsive disorder: The roles of alexithymia and attachment. Psychology and Psychotherapy: Theory, Research and Practice, 84, 367-388.

Cohen, J. (1987). Statistical power analysis for the behavioral sciences. New York, NY: Academic Press.

Collins, N.L., \& Read S.J. (1990). Adult attachment, working models, and relationship quality in dating couples. Journal of Personality and Social Psychology, 58: 644-663.

Conradi, H.J., Kamphuis, J.H., \& de Jonge, P. (2018). Adult attachment predicts the sevenyear course of recurrent depression in primary care. Journal of Affective Disorders, $225,160-166$.

Crowell, J.A., Fraley, R.C., \& Shaver, P.R. (1999). Measurement of individual differences in adolescent and adult attachment. In J. Cassidy, \& P.R. Shaver (Eds.), Handbook of attachment: Theory, research, and clinical applications (pp. 925). New York, NY: Guilford Press.

Derogatis, L.R. (1977). Administration, scoring and procedures: Manual for the revised version. Baltimore, MD: Clinical Psychometrics Research.

Doron, G., Derby, D.S., Szepsenwol, O. \& Talmor, D. (2012a). Tainted love: Exploring relationship-centered obsessive-compulsive symptoms in two non-clinical cohorts. Journal of Obsessive-Compulsive and Related Disorders, 1, 16-24

Doron, G., \& Kyrios, M. (2005). Obsessive compulsive disorder: A review of possible specific internal representations within a broader cognitive theory. Clinical Psychology Review, 25(4), 415-432.

Doron, G., Mikulincer, M., Kyrios, M., \& Sar-El, D. (2015). Integrating psychodynamic and cognitive approaches to obsessive compulsive disorder - attachment insecurities and self-related sensitivities in morality and relational domains. In L.M.P. Luyten, P. Fonagy, M. Target \& S.J. Blatt (Eds.), Handbook of contemporary psychodynamic approaches to psychopathology (pp. 199-215). New York, NY: Guilford Press.

Doron, G., \& Moulding, R. (2009). Cognitive behavioral treatment of obsessive compulsive disorder: a broader framework. Israel Journal of Psychiatry and Related Sciences, 46(4), 257-63.

Doron, G., Moulding R., Kyrios, M., Nedeljkovic, M., \& Mikulincer, M. (2009). Adult attachment insecurities are related to obsessive compulsive phenomena. Journal of Social and Clinical Psychology, 28(8), 1022-1049. 
Doron, G., Moulding, R., Nedeljkovic, M., Kyrios, M., Mikulincer, M., \& Sar-El, D. (2012b). Adult attachment insecurities are associated with obsessive compulsive disorder. Psychology and Psychotherapy: Theory, Research and Practice, 85, 163-178.

Duval S., \& Tweedie R. (2000). Trim and fill: a simple funnel-plot-based method of testing and adjusting for publication bias in meta-analysis. Biometrics, 56, 455-463.

Eddy, K.T., Dutra, L., Bradley, R., Westen, D. (2004). A multidimensional meta-analysis of psychotherapy and pharmacotherapy for obsessive-compulsive disorder. Clinical Psychology Review, 24(8), 1011-1030.

Ein-Dor, T., Viglin, D., \& Doron, G. (2016). Extending the transdiagnostic model of attachment and psychopathology. Frontiers in Psychology, 7, 1-6.

Esman, A.H. (2001). Obsessive-compulsive disorder: Current views. Psychoanalytic Inquiry, 21(2), 145-156.

Fergus, T.A., \& Rowatt, W.C. (2014). Examining a purported association between attachment to God and scrupulosity. Psychology of Religion and Spirituality, 6(3), $230-236$.

Foa, E.B., Huppert, J.D., \& Leiberg, S. (2002). The Obsessive-Compulsive Inventory: development and validation of a short version. Psychological Assessment, 14, 485496.

Fraley, R.C., \& Shaver, P.R. (1997). Adult attachment and the suppression of unwanted thoughts. Journal of Personality and Social Psychology, 73(5), 1080-91.

Fraley, R.C., Waller, N.G., \& Brennan, K.A. (2000). An item response theory analysis of self-report measures of adult attachment. Journal of Personality and Social Psychology, 78, 350-365.

Gabbard, G.O. (2005). Psychodynamic psychiatry in clinical practice (4th ed.). Washington, DC: American Psychiatric Publishing, Inc.

George, C., Kaplan, N., \& Main, M. (1984/1985/1996). The Adult Attachment Interview. Berkeley, CA: University of California, Berkeley.

Goodman, W.K., Price, 1.H., Rasmussen, S.A., Mazure, C., Fleischmann, R.L., Hill, C.L., Heninger, G.R., \& Charney, D.S. (1989). The Yale-Brown Obsessive Compulsive Scale. I. Development, use, and reliability. Archives of General Psychiatry, 46(11), 1006-1011.

Gülüm, I.V., \& Dağ, I. (2014). The mediator role of cognitive features in the relationship between adult attachment patterns and psychopathology symptoms: The locus of control and repetitive thinking. Turkish Journal of Psychiatry, 25(4), 244-252. 
Hesse, E., \& Main, M. (2000). Disorganized infant, child, and adult attachment: Collapse in behavioral and attentional Strategies. Journal of the American Psychoanalytic Association, 48(4), 1097-1127.

Higgins, J., Thompson, S.G., Deeks, J.J., \& Altman, D.G. (2003). Measuring inconsistency in meta-analyses. British Medical Journal, 327, 557-560.

Hodgson, R.J., \& Rachman, S. (1977). Obsessional-compulsive complaints. Behaviour Research and Therapy, 15, 389-395.

Kempke, S., \& Luyten, P. (2007). Psychodynamic and cognitive-behavioral approaches of obsessive-compulsive disorder: is it time to work through our ambivalence? Bulletin of the Menninger Clinic, 71(4), 291-311.

Koohsar, A.A.H., \& Bona, B.G. (2011). Relation among quality of attachment, obsessive compulsive behaviours and phobic anxiety in college students. Social and Behavioural Sciences, 30, 187-191.

Leichsenring, F., \& Steinert, C. (2017). Short-term psychodynamic therapy for obsessivecompulsive disorder: A manual-guided approach to treating the "inhibited rebel". Bulletin of the Menninger Clinic, 81(4), 341-389.

Marazziti, D., Baroni, S., Giannaccini, G., Catena-Dell'Osso, M., Piccinni, A., Massimetti, G., \& Dell'Osso, L. (2015). Plasma oxytocin levels in untreated adult obsessivecompulsive disorder patients. Neuropsychobiology, 72, 74-80.

Mikulincer, M., \& Florian, V. (1998). The relationship between adult attachment styles and emotional and cognitive reactions to stressful events. In J.A. Simpson \& W.S. Rholes (Eds.), Attachment theory and close relationships (pp. 143-165). New York, NY: Guilford Press.

Mikulincer, M., \& Shaver, P.R. (2007). Attachment in adulthood: Structure, dynamics, and change. New York, NY: Guilford Press.

Mikulincer, M., Shaver, P.R., \& Pereg, D. (2003). Attachment theory and affect regulation: The dynamics, development, and cognitive consequences of attachment-related strategies. Motivation and Emotion, 27(2), 77-102.

Moher, D., Liberati, A., Tetzlaff, J., \& Altman, D.G. (2009). Preferred reporting items for systematic reviews and meta-analyses: the PRISMA statement. Journal of Clinical Epidemiology, 62(10), 1006-1012.

Moritz, S., Kempke, S., Luyten, P., Randjbar, S., \& Jelinek, L. 2011. Was Freud partly right on obsessive-compulsive disorder (OCD)? Investigation of latent aggression in OCD. Psychiatry Research, 187, 180-184. 
Myhr, G., Sookman, D., \& Pinard, G. (2004). Attachment security and parental bonding in adults with obsessive-compulsive disorder: a comparison with depressed out-patients and healthy controls. Acta Psychiatrica Scandinavica, 109(6), 447-456.

National Institute for Health and Clinical Excellence. (2005). Obsessive-compulsive disorder, Clinical Guideline 31. London, UK: National Institute for Health and Clinical Excellence.

Nedelisky, A., \& Steele, M. (2009). Attachment to people and to objects in obsessivecompulsive disorder: an exploratory comparison of hoarders and non-hoarders. Attachment \& Human Development, 11(4), 365-83.

Nielsen, S.K.K., Hageman, I., Petersen, A., Daniel, S.I.F., Lau, M., Winding, C., WolitzkyTaylor, K.B., Steele, H., \& Vangkilde, S. (2018). Do emotion regulation, attentional control, and attachment style predict response to cognitive behavioral therapy for anxiety disorders? - an investigation in clinical settings. Psychotherapy Research, 111.

Obsessive Compulsive Cognitions Working Group (1997). Cognitive assessment of obsessive-compulsive disorder. Behaviour Research and Therapy, 35(7), 667-681.

Obsessive Compulsive Cognitions Working Group (2003). Psychometric validation of the Obsessive Beliefs Questionnaire and the Interpretations of Intrusions Inventory: part 1. Behaviour Research and Therapy, 41, 863-878.

Olatunji, B.O., Williams, B.J., Haslam, N., Abramowitz, J.S., \& Tolin, D.F. (2008). The latent structure of obsessive-compulsive symptoms: A taxometric study. Depression and Anxiety, 25(11), 956-968.

Rachman, S. (1997). A cognitive theory of obsessions. Behaviour Research and Therapy, 35(9), 793-802.

Rachman, S. (1998). A cognitive theory of obsessions: elaborations. Behaviour Research and Therapy, 36(4), 385-401.

Rapp, A.M., Bergman, L., Piacentini, J., \& McGuire, J.F. (2016). Evidence-based assessment of obsessive-compulsive disorder. Journal of Central Nervous System Disease, 8, 13 29.

Rice, K.G., Lopez, F.G., \& Vergara, D. (2005). Parental/social influences on perfectionism and adult attachment orientations. Journal of Social and Clinical Psychology, 24, 580-605.

Rosa, A.C., Diniz, J. B., Fossaluza, V., Torres, A.R., Fontenelle, L.F., De Mathis, A.S., da Conceicao Rosario, M., Miguel, E.C., \& Shavitt, R.G. (2012). Clinical correlates of 
social adjustment in patients with obsessive-compulsive disorder. Journal of Psychiatric Research, 46(10), 1286-1292.

Salkovskis, P.M. (1985). Obsessional-compulsive problems: A cognitive-behavioural analysis. Behaviour Research and Therapy, 23(5), 571-583.

Sanavio, E. (1988). Obsessions and compulsions: the Padua Inventory. Behaviour Research and Therapy, 26(2), 169-177.

Seah, R., Fassnacht, D., \& Kyrios, M. (2018). Attachment anxiety and self-ambivalence as vulnerabilities toward obsessive compulsive disorder. Journal of ObsessiveCompulsive and Related Disorders, 18, 40-46.

Sookman, D., \& Pinard, G. (1999). Integrative cognitive therapy for obsessive-compulsive disorder: A focus on multiple schemas. Cognitive and Behavioral Practice, 6(4), 351362.

Spielberger, C.D., Gorsuch, R.L., Lushene, R., Vagg, P.R., \& Jacobs, G.A. (1983). Manual for the State-Trait Anxiety Inventory. Palo Alto, CA: Consulting Psychologists Press.

Storch, E.A., Benito, K., \& Goodman, W. (2011). Assessment scales for obsessivecompulsive disorder. Neuropsychiatry, 1(3), 243-250.

Thiel, N., Jacob, G.A., Tuschen-Caffier, B., Herbst, N., Külz, A.K., Hertenstein, E., Nissen, C., \& Voderholzer, U. (2016). Schema therapy augmented exposure and response prevention in patients with obsessive-compulsive disorder: Feasibility and efficacy of a pilot study. Journal of Behavior Therapy and Experimental Psychiatry, 52, 59-67.

Tibi, L., van Oppen, P., van Balkom, A.J.L.M., Eikelenboom, M., Rickelt, J., Schruers, K.R. J., \& Anholt, G.E. (2017). The long-term association of OCD and depression and its moderators: A four-year follow up study in a large clinical sample. European Psychiatry, 44, 76-82.

Tolin, D.F., Meunier, S.A., Frost, R.O., \& Steketee, G. (2011). Hoarding among patients seeking treatment for anxiety disorders. Journal of Anxiety Disorders, 25(1), 43-48.

Warren, S.L., Huston, L., Egeland, B., \& Sroufe, L.A. (1997). Child and adolescent anxiety disorders and early attachment. Journal of the American Academy of Child and Adolescent Psychiatry, 36(5), 637-644.

Waters, E., Merrick, S., Treboux, D., Crowell, J., Albersheim, L. (2000). Attachment security in infancy and early adulthood: A twenty-year longitudinal study. Child Development, 71(3): 684-689. 
Wei, M., Mallinckrodt, B., Russell, D.W., \& Abraham, W.T. (2004). Maladaptive perfectionism as a mediator and moderator between adult attachment and depressive mood. Journal of Counseling Psychology, 51(2), 201-212.

Wei, M., Russell, D.W., Mallinckrodt, B., \& Vogel, D.L. (2007). The Experiences in Close Relationship Scale (ECR)-short form: Reliability, validity, and factor structure. Journal of Personality Assessment, 88, 187-204

West, M., \& Sheldon-Keller, A. (1992). The assessment of dimensions relevant to adult reciprocal attachment. Canadian Journal of Psychiatry, 37, 600-606.

Wilcox, H.C., Grados, M., Samuels, J., Riddle, M.A., Bienvenu, O.J., Pinto, A., Cullen, B., Wang, Y., Shugart, Y.Y., Liang, K.Y., \& Nestadt, G. (2008). The association between parental bonding and obsessive compulsive disorder in offspring at high familial risk. Journal of Affective Disorders, 111(1), 31-39.

Woodhouse, S., Ayers, S., \& Field, A.P. (2015). The relationship between adult attachment style and post-traumatic stress symptoms: A meta-analysis. Journal of Anxiety Disorders, 35, 103-117. 


\section{Table 1. Characteristics and main results of included studies}

\begin{tabular}{|c|c|c|c|c|c|c|c|c|c|c|c|}
\hline Author & Year & Country & $N$ & $\begin{array}{l}\text { Study } \\
\text { design }\end{array}$ & $\begin{array}{l}\text { Attachment } \\
\text { assessment }\end{array}$ & OCD assessment & Population & $\begin{array}{l}\text { Age } \\
\text { (Mean) }\end{array}$ & $\begin{array}{l}\text { Female } \\
(\%)\end{array}$ & $\begin{array}{l}\text { Single } \\
(\%)\end{array}$ & Main results \\
\hline Alcee & 2006 & USA & $\begin{array}{l}\text { OCD- } \\
\text { analogue: } \\
\\
\text { HC: } \quad 113\end{array}$ & $\mathrm{C}-\mathrm{C}$ & $\begin{array}{l}\text { ECR-R } \\
\text { (romantic partners) } \\
\text { Anx / Avoid }\end{array}$ & $\begin{array}{l}\text { OCI } \\
\text { STAI } \\
\text { Self-report } \\
\text { OCD cut-off: } \\
\geq 40 \text { on OCI and } \\
\geq 45 \text { on STAI }\end{array}$ & $\begin{array}{l}\text { University students. } \\
\text { HC group had STAI } \\
\text { scores between } 32 \text { and } \\
45 .\end{array}$ & $\begin{array}{l}\text { OCD: } 19.2 \\
\text { HC: } 19.5\end{array}$ & $\begin{array}{l}\text { OCD: } 78 \\
\text { HC: } \quad 58\end{array}$ & - & $\begin{array}{l}\text { OC-analogue: Anx and not } \\
\text { Avoid predicted OC symp } \\
\text { HC: Anx and not Avoid } \\
\text { predicted OCD symp, } \\
\text { controlled for trait anxiety }\end{array}$ \\
\hline $\begin{array}{l}\text { Asad and } \\
\text { Dawood }\end{array}$ & 2015 & Pakistan & OCD: 90 & Corr & $\begin{array}{l}\text { RAAS } \\
\text { (romantic partners) } \\
\text { Anx }=\text { Anxious } \\
\text { scale } / \text { Avoid }= \\
\text { close and depend } \\
\text { scale combined }\end{array}$ & $\begin{array}{l}\text { OCD } \\
\text { Symptom } \\
\text { Checklist: } \\
\text { Obsession scale } \\
\text { Self-report }\end{array}$ & $\begin{array}{l}\text { Referrals with OCD } \\
\text { diagnosis from city } \\
\text { hospitals, confirmed } \\
\text { with self-report } \\
\text { screening instrument. } \\
\text { Comorbid depression: } \\
51 \% \text {. }\end{array}$ & 28.6 & 52 & 58 & $\begin{array}{l}\text { No correlation between Anx or } \\
\text { Avoid and any of obsession or } \\
\text { compulsion symptom } \\
\text { dimension }\end{array}$ \\
\hline Boelen et al. & 2014 & Netherlands & $\begin{array}{l}\text { General: } \\
215\end{array}$ & Corr & $\begin{array}{l}\text { ECR-R } \\
\text { (romantic partners) } \\
\text { Anx / Avoid }\end{array}$ & $\begin{array}{l}\text { OCI-R } \\
\text { Self-report }\end{array}$ & $\begin{array}{l}\text { University students. } \\
\text { All: elevated } \\
\text { separation anxiety } \\
\text { scores. No elevated } \\
\text { mean levels of } \\
\text { depression or OC } \\
\text { symptoms scores. }\end{array}$ & 21.6 & 92 & 32 & $\begin{array}{l}\text { Positive correlation Avoid/Anx } \\
\text { and OC symp } \\
\text { Correlation Avoid holds when } \\
\text { controlled for Anx, } \\
\text { neuroticism, gender, age and } \\
\text { singleness }\end{array}$ \\
\hline $\begin{array}{l}\text { Boysan and } \\
\text { Çam }\end{array}$ & 2018 & Turkey & $\begin{array}{l}\text { General: } \\
329\end{array}$ & Corr & $\begin{array}{l}\text { ECR-R } \\
\text { (close } \\
\text { relationships) } \\
\text { Anx / Avoid }\end{array}$ & $\begin{array}{l}\text { PI-R } \\
\text { OBQ } \\
\text { Self report }\end{array}$ & University students. & 19.2 & 56 & - & $\begin{array}{l}\text { Positive correlation Avoid/Anx } \\
\text { and OC symp (total and all } \\
\text { subscales), controlled for age, } \\
\text { gender, income } \\
\text { Fearful }>\text { Anx }>\text { Avoid }= \\
\text { Secure }\end{array}$ \\
\hline
\end{tabular}




\section{Table 1. Characteristics and main results of included studies}

\begin{tabular}{|c|c|c|c|c|c|c|c|c|c|c|c|c|}
\hline $\begin{array}{l}\text { Carpenter } \\
\text { and Chung }\end{array}$ & 2011 & $\begin{array}{l}\text { Global } \\
\text { (Mostly } \\
\text { western) }\end{array}$ & $\begin{array}{l}\text { OCD: } \\
\text { HC: }\end{array}$ & $\begin{array}{l}82 \\
92\end{array}$ & $\mathrm{C}-\mathrm{C}$ & $\begin{array}{l}\text { ECR } \\
\text { (close } \\
\text { relationships) } \\
\text { Anx / Avoid }\end{array}$ & $\begin{array}{l}\text { YBOCS-SR } \\
\text { Self report } \\
\text { OCD cut-off: } \\
\geq 8 \text { on either } \\
\text { obsessive or } \\
\text { compulsive scale }\end{array}$ & $\begin{array}{l}\text { Visitors of websites: } \\
\text { Self-help groups / } \\
\text { research websites; } \\
\text { Informal networks. } \\
\text { Mean severity OCD: } \\
\text { moderate (YBOCS). } \\
\text { Diverse symptoms. }\end{array}$ & $\begin{array}{l}\text { OCD: } 28.2 \\
\text { HC: } 33.9 \\
*\end{array}$ & $\begin{array}{l}\text { OCD: } 76 \\
\text { HC: } 86\end{array}$ & $\begin{array}{l}\text { OCD: } 37 \\
\text { HC: } 29\end{array}$ & $\begin{array}{l}\text { Higher Anx and Avoid in OCD } \\
\text { vs HC } \\
\text { OCD: Anx and Avoid } \\
\text { correlated to severity and } \\
\text { number of obsessions, but not } \\
\text { compulsions }\end{array}$ \\
\hline Doron et al. & 2009 & Australia & Genera & 1: 446 & Corr & $\begin{array}{l}\text { ECR } \\
\text { (close } \\
\text { relationships) } \\
\text { Anx / Avoid }\end{array}$ & $\begin{array}{l}\text { PI-R } \\
\text { OBA } \\
\text { Self report }\end{array}$ & $\begin{array}{l}\text { University students; } \\
\text { No current or past } \\
\text { mental problems. }\end{array}$ & 21.3 & 81 & - & $\begin{array}{l}\text { Positive correlation Avoid/Anx } \\
\text { and OC symp } \\
\text { Mediated by OCD-beliefs } \\
\text { Correlation stays significant } \\
\text { when controlled for mood }\end{array}$ \\
\hline Doron et al. & $2012 \mathrm{a}$ & Israel & Genera & 1: 179 & Corr & $\begin{array}{l}\text { ECR-SF } \\
\text { (romantic partners) } \\
\text { Anx / Avoid }\end{array}$ & $\begin{array}{l}\text { OCI } \\
\text { Self report }\end{array}$ & Visitors of website. & 37.0 & 51 & 21 & $\begin{array}{l}\text { Positive correlation Avoid/Anx } \\
\text { and OC symp }\end{array}$ \\
\hline Doron et al. & $2012 b$ & Australia & $\begin{array}{l}\text { OCD: } \\
\text { HC: }\end{array}$ & $\begin{array}{l}30 \\
32\end{array}$ & $\mathrm{C}-\mathrm{C}$ & $\begin{array}{l}\text { ECR } \\
\text { (close } \\
\text { relationships) } \\
\text { Anx / Avoid }\end{array}$ & $\begin{array}{l}\text { OCD: DSM-IV } \\
\text { Interview }\end{array}$ & $\begin{array}{l}\text { OCD: psychology } \\
\text { clinics, consumer } \\
\text { groups, advertise- } \\
\text { ments. Mean severity } \\
\text { OCD: mild (PI-R). } \\
\text { Diverse symptoms. } \\
23 \% \text { DD; } 37 \% \text { AD. } \\
\text { HC: } \\
\text { Hospital staff, } \\
\text { university students, } \\
\text { working population. } \\
\text { No current or past } \\
\text { mental problems. }\end{array}$ & $\begin{array}{l}\text { OCD: } 37.6 \\
\text { HC: } 29.8\end{array}$ & $\begin{array}{l}\text { OCD: } 60 \\
\mathrm{HC}: \quad 50\end{array}$ & $\begin{array}{l}\text { OCD: } 53 \\
\mathrm{HC}: \quad-\end{array}$ & $\begin{array}{l}\text { Higher Anx in OCD vs HC } \\
\text { When controlled for mood: } \\
\text { effect size decreases, though } \\
\text { still significant }\end{array}$ \\
\hline $\begin{array}{l}\text { Fergus } \\
\text { and Rowatt }\end{array}$ & 2014 & USA & Genera & 1: 450 & Corr & $\begin{array}{l}\text { ECR-R } \\
\text { (close } \\
\text { relationships) } \\
\text { Anx/Avoid }\end{array}$ & $\begin{array}{l}\text { DOCS } \\
\text { Self report }\end{array}$ & $\begin{array}{l}\text { Visitors of website. } \\
57.3 \% \text { college degree. }\end{array}$ & 33.7 & 59 & 37 & $\begin{array}{l}\text { Positive correlation Avoid/Anx } \\
\text { and OC symp }\end{array}$ \\
\hline
\end{tabular}




\section{Table 1. Characteristics and main results of included studies}

\begin{tabular}{|c|c|c|c|c|c|c|c|c|c|c|c|c|c|c|}
\hline $\begin{array}{l}\text { Gülüm } \\
\text { and Dağ }\end{array}$ & 2014 & Turkey & Genera & 875 & Corr. & $\begin{array}{l}\text { ECR-R } \\
\text { (close } \\
\text { relationships) } \\
\text { Anx / Avoid }\end{array}$ & $\begin{array}{l}\text { MOCI } \\
\text { Self report }\end{array}$ & University students. & 21.0 & & 66 & & - & $\begin{array}{l}\text { Positive correlation Avoid/Anx } \\
\text { and OC symp } \\
\text { Results reported separately for } \\
\text { male and female }\end{array}$ \\
\hline $\begin{array}{l}\text { Koohsar } \\
\text { and Bona }\end{array}$ & 2011 & Iran & Genera & 469 & Corr & $\begin{array}{l}\text { RAAS } \\
\text { (romantic partners) } \\
\text { Anx }=\text { Anxious } \\
\text { scale } / \text { Avoid }= \\
\text { Close scale }\end{array}$ & $\begin{array}{l}\text { SCL-90-R-OC } \\
\text { Self report }\end{array}$ & University students. & $18-25$ & & 53 & & 89 & $\begin{array}{l}\text { Positive correlation Avoid/Anx } \\
\text { and OC symp }\end{array}$ \\
\hline $\begin{array}{l}\text { Marazziti } \\
\text { et al. }\end{array}$ & 2015 & Italy & $\begin{array}{l}\text { OCD: } \\
\text { HC: }\end{array}$ & $\begin{array}{l}44 \\
44\end{array}$ & $\mathrm{C}-\mathrm{C}$ & $\begin{array}{l}\text { ECR } \\
\text { (romantic partners) } \\
\text { Anx / Avoid }\end{array}$ & $\begin{array}{l}\text { OCD: DSM-IV } \\
\text { Interview }\end{array}$ & $\begin{array}{l}\text { OCD: outpatient unit. } \\
\text { No depression. } \\
\text { Mean severity OCD: } \\
\text { severe (YBOCS). } \\
\text { Diverse symptoms. } \\
\text { HC: No current or past } \\
\text { mental problems. }\end{array}$ & $\begin{array}{l}\text { OCD: } 29.2 \\
\text { HC: } 28.3\end{array}$ & $\begin{array}{l}\text { OCD: } \\
\mathrm{HC}:\end{array}$ & $\begin{array}{l}48 \\
48\end{array}$ & $\begin{array}{l}\text { OCD: } \\
\mathrm{HC}:\end{array}$ & $\begin{array}{l}64 \\
68\end{array}$ & $\begin{array}{l}\text { Higher Anx and Avoid in OCD } \\
\text { vs HC }\end{array}$ \\
\hline Myhr et al. & 2004 & Canada & $\begin{array}{l}\text { OCD: } \\
\text { HC: }\end{array}$ & $\begin{array}{l}36 \\
26\end{array}$ & $\mathrm{C}-\mathrm{C}$ & $\begin{array}{l}\text { RAAS } \\
\text { (romantic partners) } \\
\text { Anx = Anxious } \\
\text { scale }\end{array}$ & $\begin{array}{l}\text { OCD: DSM-IV } \\
\text { Interview }\end{array}$ & $\begin{array}{l}\text { OCD: outpatient unit. } \\
69 \% \text { secondary } \\
\text { depression. } \\
\text { Mean severity OCD: } \\
\text { moderate (YBOCS). } \\
\text { HC: hospital staff with } \\
\text { diverse socio- } \\
\text { economic status. } \\
\text { No current or past } \\
\text { mental problems. }\end{array}$ & $\begin{array}{l}\text { OCD: } 29.3 \\
\text { HC: } 37.4 \\
*\end{array}$ & $\begin{array}{l}\text { OCD: } \\
\mathrm{HC}:\end{array}$ & $\begin{array}{l}47 \\
69\end{array}$ & $\begin{array}{l}\text { OCD: } \\
\text { HC: } \\
*\end{array}$ & $\begin{array}{l}75 \\
31\end{array}$ & $\begin{array}{l}\text { Higher Anx in OCD vs HC } \\
\text { Controlled for mood } \\
\text { [Avoid not in meta-analysis } \\
\text { due to incomplete data] }\end{array}$ \\
\hline $\begin{array}{l}\text { Nedelisky } \\
\text { and Steele }\end{array}$ & 2009 & USA & OCD: & 30 & Corr & $\begin{array}{l}\text { RAQ } \\
\text { (romantic partners) } \\
\text { Anx = Feared loss } \\
\text { scale / Avoid = } \\
\text { Secure base scale }\end{array}$ & $\begin{array}{l}\text { OCD: DSM-IV } \\
\text { Interview } \\
\text { YBOCS }^{\mathrm{MA}} \\
\text { Self report }\end{array}$ & $\begin{array}{l}\text { Psychiatric clinic; } \\
\text { OCD support groups. } \\
47 \% \text { hoarding } \\
\text { symptomatology. } \\
\text { Mean severity OCD: } \\
\text { severe-extreme } \\
\text { (YBOCS). }\end{array}$ & 46.1 & & 47 & & 63 & $\begin{array}{l}\text { Positive correlation Avoid/Anx } \\
\text { and OCD severity } \\
\text { Female higher than male in } \\
\text { attachment insecurity }\end{array}$ \\
\hline Seah et al. & 2018 & Australia & \multicolumn{2}{|c|}{ General: } & Corr & ECR-SF & OCI-R & Recruited via online & 23.2 & & 75 & & 77 & Positive correlation Anx and \\
\hline
\end{tabular}




\section{Table 1. Characteristics and main results of included studies}

439

(close
relationships)
Anx

Self report

\section{Tibi et al.}

\begin{abstract}
Netherlands

OCD: 348 Corr
\end{abstract}

Self report
RQ

(close relationships)

Anx $=$ preoccupied

Avoid $=$ dismissing$$
\text { flyers. }
$$

$87 \%$ university

students

$27.6 \%$ within clinical

range of OCD
OCD: DSM-IV

Interview

YBOCS $^{\mathrm{MA}}$

Clinician rated
OCD: multicenter

cohort.

Mean severity OCD

moderate (YBOCS).
OC symp

\section{Explanation of abbreviations and terms, ordered by columns}

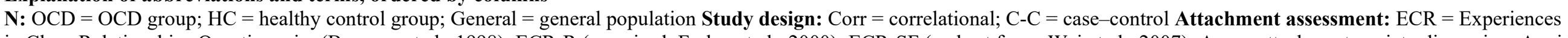

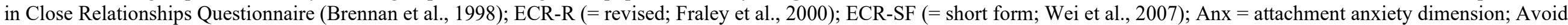

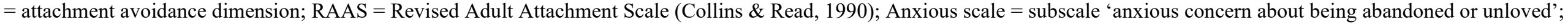

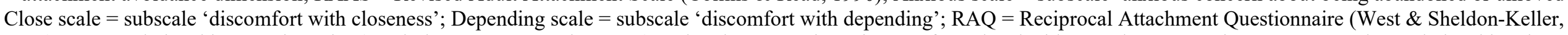

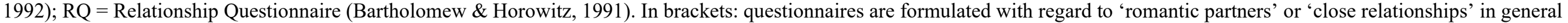

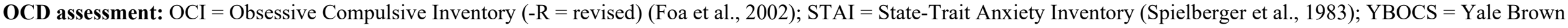

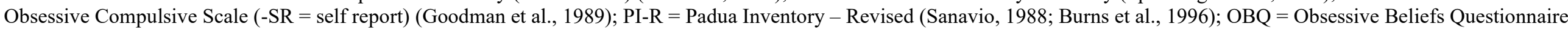

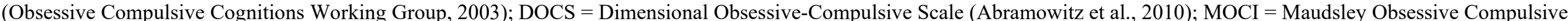

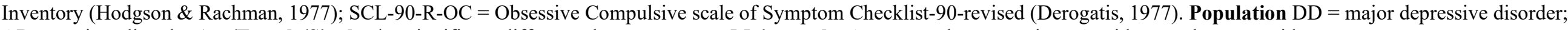
$\mathrm{AD}=$ anxiety disorder Age/Female/Single: * = significant difference between groups Main results Anx = attachment anxiety; Avoid = attachment avoidance; symp = symptoms 


\section{Table 1. Characteristics and main results of included studies}

\begin{tabular}{|c|c|}
\hline $\begin{array}{l}\text { Groupby } \\
\text { Population }\end{array}$ & Studyname \\
\hline Genera & Bodenetd., 2014 \\
\hline Genera & Bosen\& \& ̧̧am 2018 \\
\hline Generd & Daronetal., 2009 \\
\hline Generd & Doroned.t., 2012a \\
\hline Genera & Fergus \&Ronett, 2014 \\
\hline Generd & Glium\&Dag, 2014 \\
\hline Genera & Gilüm\&Dag, 2014 \\
\hline Generd & Koosher \&Bona, 2011 \\
\hline \multirow{2}{*}{\multicolumn{2}{|c|}{ Sechedtal, 2018}} \\
\hline & \\
\hline$\bigcirc C D$ & $A_{0 œ,}, 2006$ \\
\hline$O C D$ & Asad\&Danood, 2015 \\
\hline$O C D$ & Capenter \&Chung, 2011 \\
\hline$O C D$ & Daroneta., 20120 \\
\hline$\infty C D$ & Meraziti etal., 2015 \\
\hline$\infty O D$ & Mytr eda., 2004 \\
\hline$O C D$ & Nedelisky\&Siede, 2009 \\
\hline$\propto C D$ & Tibi et d., 2017 \\
\hline & \\
\hline Oerall & \\
\hline
\end{tabular}

Subgroup
none
none
none
none
nore
Men
Whnen
none
none
none
none
none
none
none
none
none
none

\section{ges's Standard Low Unerd}

\begin{tabular}{|c|c|c|c|c|c|}
\hline $\begin{array}{l}\text { andar } \\
\text { eror }\end{array}$ & Variance & limer & $\begin{array}{l}\text { Upper } \\
\text { limit }\end{array}$ & z & \\
\hline 0,139 & 0,019 & 0,069 & 0,003 & 2388 & 0,017 \\
\hline 0,125 & 0,016 & 0,817 & 1,308 & 8,486 & \\
\hline 0,100 & 0,010 & 0,501 & 0,895 & 6,946 &, 000 \\
\hline 0,154 & 0,024 & 0,168 & 0,73 & 3,061 & $0, \infty$ \\
\hline 0,101 & 0,010 & 0,548 & 0,944 & 7,400 & \\
\hline 0,126 & 0,016 & 0,548 & 1,041 & 6,312 & \\
\hline 0,087 & 0,007 & 0,413 & 0,752 & 6,732 & $0, \infty$ \\
\hline 0,099 & 0,010 & 80 & 0,965 & 7,771 & \\
\hline 0,102 & 0,010 & 0,523 & 0,921 & 7,009 & \\
\hline 0,000 & 0,004 & & 0,812 & 11,566 & \\
\hline 0,238 & 0,067 & 0,411 & 1,343 & 3,687 & \\
\hline 0,213 & 0,046 & & 0,598 & 0,399 & \\
\hline 0,156 & 0,024 & & 1,027 & 4,620 & \\
\hline 0,269 & 0,072 & 39 & 1,592 & 3,999 & \\
\hline 0,215 & 0,046 & 34 & 0,979 & 2584 & \\
\hline 0,266 & 0,071 & 0,358 & 1,401 & 3,304 & $a$ \\
\hline 0,442 & 0,195 & & 2002 & 2754 & \\
\hline 0,109 & 12 & 0,267 & 0,159 & $-0,496$ & \\
\hline 0,176 & & & 0,975 & 3,564 & \\
\hline & 0,003 & & 99 & 12107 & \\
\hline
\end{tabular}

Hedges'sgand $95 \% \mathrm{Cl}$

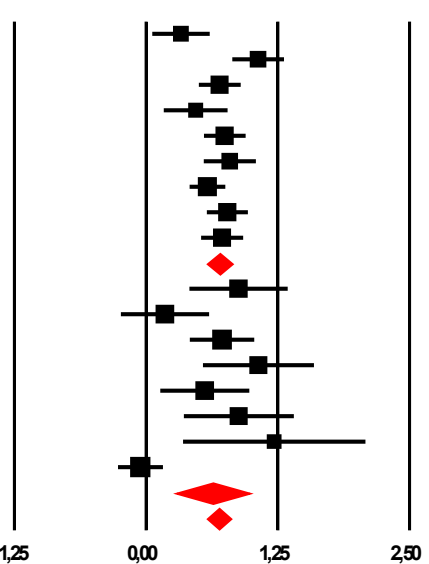

Figure 2. Forest plot of studies reporting the relationship between attachment anxiety and OCD symptoms: overall effect size and effect size grouped by population (OCD population and general population with OCD symptoms) are reported. Analyses with random effects model. 


\section{Table 1. Characteristics and main results of included studies}

\begin{tabular}{|c|c|c|}
\hline$\frac{\text { Groupby }}{\text { Population }}$ & Studyname & $\underline{\text { Subgroup }}$ \\
\hline Generd & Bodenetal. 2014 & none \\
\hline Generd & Basen\& \&cam 2018 & none \\
\hline Genera & Doronetal., 2009 & none \\
\hline Generd & Doronedal., 2012a & none \\
\hline Generd & Fergus \& Rowatt, 2014 & none \\
\hline Genera & Gilüm\&Dag,2014 & Men \\
\hline Generd & Gilüm\&Dag 2014 & Wern \\
\hline \multirow{2}{*}{\multicolumn{3}{|c|}{ Kooster \&Bona, 2011}} \\
\hline & & \\
\hline$\propto D$ & A 10,2006 & none \\
\hline$\triangle O D$ & Ased \&Danood, 2015 & none \\
\hline$\propto$ & Capenter \&Chung. 2011 & none \\
\hline$\triangle C D$ & Doroneta., 20120 & none \\
\hline OCD & Mrazified ad 2015 & none \\
\hline$\infty \subset D$ & 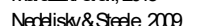 & none \\
\hline \multirow{2}{*}{\multicolumn{3}{|c|}{ Tibi etal., 2017}} \\
\hline & & \\
\hline Oerall & & \\
\hline
\end{tabular}

\begin{tabular}{|c|c|c|c|c|c|c|}
\hline \multirow[b]{2}{*}{$\begin{array}{c}\text { Hedges's } \\
\text { g }\end{array}$} & \multicolumn{4}{|c|}{ Statistics for each study } & \multirow[b]{2}{*}{ Z-Value } & \multirow[b]{2}{*}{$\mathrm{p}$-Value } \\
\hline & $\begin{array}{c}\text { Standard } \\
\text { eror }\end{array}$ & Variance & $\begin{array}{l}\text { Lover } \\
\text { limit }\end{array}$ & $\begin{array}{c}\text { Upper } \\
\text { limit }\end{array}$ & & \\
\hline 0,550 & 0,142 & 0,020 & 0.272 & 0,228 & 3873 & 0,000 \\
\hline & 0,116 & 0,013 & 0,400 & 0,855 & 5,417 & 0,000 \\
\hline 29 & 0,097 & 0,009 & 0,239 & 0,619 & 4,420 & 0,000 \\
\hline & 0,154 & 0,024 & 0,127 & 0,729 & 2780 & 005 \\
\hline & 0,008 & 0,010 & 0,308 & 0,752 & 5,708 & $\infty$ \\
\hline & 0,120 & 0,015 & 0,27 & 0,729 & 4,094 & 000 \\
\hline & 0,085 & 0,007 & 0,305 & 0,039 & 5,500 & 0,000 \\
\hline 0,282 & 0,093 & 0,009 & 0,009 & 0,465 & 3,022 & 0,003 \\
\hline & 0,099 & 0,002 & 0,393 & 0,546 & 12,074 & 0,000 \\
\hline & 0,236 & 0,066 & 0,144 & 1,069 & $25 / 2$ & 0,010 \\
\hline & 0.213 & 0.045 & $-0,259$ & 0.57 & 0,746 & 0.456 \\
\hline & 0,156 & 0,024 & 0,421 & 1.034 & 4,609 & 0,000 \\
\hline 0,515 & 0,256 & 0,065 & 0,015 & $\begin{array}{l}1,015 \\
1,015\end{array}$ & 2018 & 0,044 \\
\hline & 0,215 & 0,046 & 0,134 & 0,979 & 2584 & 0,010 \\
\hline & 0,413 & 0,170 & 0,092 & 1,709 & 2182 & 0,029 \\
\hline & 0,107 & 0,012 & $-0,249$ & 0,173 & $-0,353$ & 0,724 \\
\hline & 0,152 & 0,023 & 0,148 & 0,743 & 2997 & \\
\hline & 0.038 & 0,001 & 0394 & 0.542 & 12425 & 0,000 \\
\hline
\end{tabular}

Hedges's gand $95 \% \mathrm{Cl}$

Figure 3. Forest plot of studies reporting the relationship between attachment avoidance and OCD symptoms: overall effect size and effect size grouped by population (OCD population and general population with OCD symptoms) are reported. Analyses with random effects model. 